DOI 10.37882/2500-3682.2021.02.31

\title{
ПСИХОФИЗИОЛОГИЧЕСКИЙ СТАТУС СТУДЕНТОВ В АСПЕКТЕ КОГНИТИВНЫХ СТИЛЕЙ ОБУЧЕНИЯ
}

\section{PSYCHOPHYSIOLOGICAL STATUS OF STUDENTS IN ASPECT COGNITIVE LEARNING STYLES}

\section{T. Yadrischenskaya}

Summary: The article examines group psychophysiological indicators of students, such as the speed of a simple visual-motor reaction, characteristics of attention, the volume of short-term sensory memory, typological properties of the nervous system, autonomic balance, biorhythms, individual profile of interhemispheric asymmetry from the standpoint of psychophysiological status, which is determined -divides cognitive stylistic capabilities of learning youth in educational activities. The study of individual and group profiles of the psychophysiological status of students contributes to the formation of a psychophysiological model of the learning process at a university. Taking into account the psychophysiological equivalents of cognitive styles, recommendations were made for students and teachers to improve the efficiency of the educational process.

Keywords: psychophysiological status, cognitive learning styles, typological properties, vegetative balance, characteristics of attention, daily biorhythms, reaction rate, sensory memory volume, brain asymmetry profile

\section{Введение}

сихофизиологический статус - это особенности организма и личности человека, определяющие потенциальные или реализуемые возможности к профессиональному обучению и заданным требованиям надежности и эффективности конкретной профессиональной деятельности [4].

Психофизиологический статус индивида характеризуется как отдельными показателями (нейродинамическими, психодинамическими, физиологическими), так и интегральными свойствами личности (когнитивными стилями, особенностями темперамента). Основные свойства нервной системы, как генетически детерминированные задатки способностей, связанные с особенностями строения и функционирования головного мозга, обусловливают фенотипическое проявление потенциала конкретного индивида $[1 ; 6 ; 10]$.

Разработка концепции психофизиологической модели процесса обучения связана с дальнейшим изучением и внедрением в практику такого понятия как

\author{
ядрищенская Татьяна Васильевна \\ К.б.н., дочент, Тихоокеанский государственный \\ университет, г. Хабаровск \\ tagir.on-line@mail.ru
}

Аннотация: В статье рассматриваются групповые психофизиологические показатели студентов, такие как скорость простой зрительно-моторной реакции, характеристики внимания, объем кратковременной сенсорной памяти, типологические свойства нервной системы, вегетативный баланс, биоритмы, индивидуальный профиль межполушарной асимметрии с позиций психофизиологического статуса, который определяет когнитивные стилевые возможности обучающейся молодежи в образовательной деятельности. Изучение индивидуальных и групповых профилей психофизиологического статуса студентов способствует формированию психофизиологической модели процесса обучения в вузе. С учетом психофизиологических эквивалентов когнитивных стилей были составлены рекомендации для студентов и преподавателей для повышения эффективности образовательного процесса.

Ключевые слова: психофизиологический статус, когнитивные стили обучения, типологические свойства, вегетативный баланс, характеристики внимания, суточные биоритмы, скорость реакции, объем сенсорной памяти, профиль асимметрии мозга.

индивидуальный когнитивный стиль. Согласно представлениям исследователей, индивидуальные различия в способах восприятия информации, приемах анализа, структурирования и оценивания своего окружения образуют некоторые типичные формы интеллектуального поведения, относительно которых группы людей являются похожими и одновременно отличными от других людей, таким образом, когнитивные стили подчиняются действию некоторых общих закономерностей организации когнитивной сферы человека. С другой стороны, выраженность тех или иных когнитивных стилей свидетельствует о сформированности «внутри» опыта индивидуума определенных уникальных индивидуально-специфических механизмов регуляции его интеллектуальной активности [11].

Существующие в настоящее время научные концепции когнитивных стилей построены, в основном, на индивидуальных психологических различиях и практически не затрагивают психофизиологические особенности. Таким образом, в современных условиях возникает потребность более углубленной проработки с позиций психофизиологического подхода существующих инди- 
видуальных стилей обучения, выявление коррелятивных связей между свойствами этих стилей и различными психологическими и поведенческими особенностями их проявления в образовательной среде, что создаст базу для формирования психофизиологической модели процесса обучения.

Целью нашего исследования явилась оценка индивидуального профиля и группового психофизиологического статуса студентов для формирования психофизиологических эквивалентов когнитивных стилей и составления рекомендаций по оптимизации процесса обучения в вузе.

\section{Материалы и методы исследования}

Оценка психофизиологического профиля студентов производилась по результатам обработки данных психофизиологических показателей, определяемых с использованием компьютерного аппаратного комплекса «НС-ПсихоТест» компании Нейрософт г. Иваново, а также с использованием бланкового анкетирования по авторским методикам.

Психофизиологический профиль студентов в нашем исследовании включает следующие показатели (рис. 1):

1. Концентрация внимания - способность к сосредоточению, оценивалась с помощью аппаратного комплекса «НС-ПсихоТест», методика «Оценка внимания» [7].
2. Устойчивость внимания - способность к длительному удержанию оценивалась с помощью компьютерного комплекса «НС-ПсихоТест», методика «Оценка внимания» [7].

3. Функциональный уровень системы - ФУС - определяется абсолютными значениями времени ПЗМР (положение вариационной кривой относительно оси абцисс), вычисляется программой «НС-ПсихоТест», методика «Оценка внимания» [7].

4. Устойчивость реакции - УР - интерпретируется как устойчивость состояния центральной нервной системы (обратно пропорциональна показателю рассеивания времени реакции), вычисляется программой «НС-ПсихоТест», методика «Оценка внимания» [7].

5. Уровень функциональных возможностей - УФВ - отражает способность обследуемого формировать адекватную заданию функциональную систему и достаточно долго ее удерживать; вычисляется программой «НС-ПсихоТест», методика «Оценка внимания» [7].

6. Оценка скорости простой зрительно-моторной реакции (ПЗМР) - показывает качество подвижности нервных процессов, скорость реакции, оценивалась с помощью компьютерного аппаратного комплекса «НС-ПсихоТест», методика «Простая зрительно-моторная реакция» [7].

7. Оценка баланса процессов возбуждения-торможения - оценивается баланс процессов возбуждения и торможения в центральной нервной

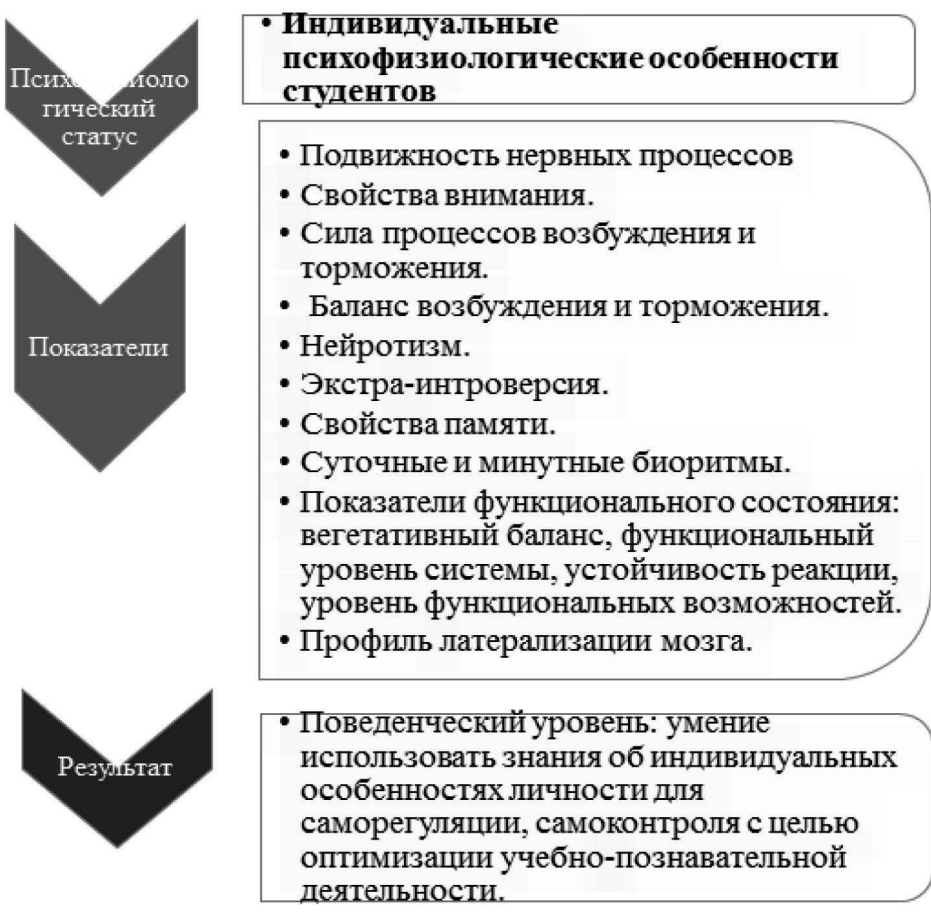

Рис. 1. Психофизиологический статус студентов ТОГУ: исследуемые показатели и значение. 
системе, оценивалась с помощью комплекса «НСПсихоТест», методика «Реакция на движущийся объект» [7].

8. Оценка объема кратковременной зрительной памяти - оценивается способность к одновременному кратковременному удержанию в памяти зрительных объектов, методика В. В. Мельникова «Зрительные матрицы» [15].

9. Оценка объема кратковременной слуховой памяти - оценивается способность к одновременному кратковременному удержанию в памяти слов, методика В. В. Мельникова «Словесная память» [15].

10. Оценка вегетативного баланса - оценивается текущее функциональное состояние организма по эйтонии (нормотонии), парасимпатикотонии (ваготонии) и симпатикотонии с использованием методик: вегетативные пробы, восьмицветовой тест М. Люшера [7].

11. Оценка силы процессов возбуждения - оценивается работоспособность нервной системы по опроснику «Черты характера, темперамента» (ЧХТ), сокращенный вариант.

12. Оценка силы процессов торможения - оценивается выдержанность, терпеливость по опроснику «Черты характера, темперамента» (ЧХТ).

13. Оценка уравновешенности процессов возбуждения и торможения - высчитывается соотношение между количественными показателями силы процессов возбуждения и торможения по опроснику чXT.

14. Оценка подвижности нервных процессов - оценивается по опроснику ЧХТ.

15. Оценка экстраверсии-интроверсии - качества определяли с использованием личного опросника Г. Айзенка.

16. Оценка нейротизма - проводилась на основе личного опросника Г. Айзенка.

17. Оценка суточных биоритмов - определяли суточные хронотипы студентов с использованием анкеты Хорна-Остберга.

18. Оценка индивидуальной минуты - позволяет оценить чувство времени к кратковременным интервалам по методике Ф. Халберга [8].

19. Оценка индивидуального профиля асимметрии производилась с использованием комплексного подхода на основе тестирования моторной и сенсорной асимметрии функций организма и определением коэффициента функциональной асимметрии [2].

В исследовании приняли участие 1157 студентов направления «Педагогическое образование»; направления «Психология», направления «Экология и природопользование» Педагогического института Тихоокеанского государственного университета, Дальневосточного государственного гуманитарного университета. Результа- ты тестирования были обработаны с помощью пакета статистических программ Microsoft Excel.

\section{Результаты исследования и обсужление}

Оценка психофизиологического статуса исследуемой студенческой группы позволила установить некоторые тенденции по направленности отдельных психофизиологических показателей в обследуемой группе студентов.

Такими показателями являются:

1. Скорость простой зрительно-моторной реакции, которая у большинства студентов трактуется как подвижный и промежуточный тип. Среднее значение простой сенсо-моторной реакции в нашем исследовании составило 270,7 мс, что свидетельствует о достаточно хороших психофизиологических ресурсах и, в целом, характеризует функциональное состояние исследуемых студентов, как находящееся в пределах психофизиологической нормы [16]. Н.А. Литвиновой были получены данные, которые свидетельствуют о значительном влиянии нейродинамических свойств на процессе адаптации студентов в вузе [5]. Исследования показывают, что студенты, обладающие высоким уровнем подвижности и силы нервных процессов, характеризуются успешностью в учебной деятельности, устойчивостью к стрессу и балансом тонуса симпатической и парасимпатической нервной системы в отличие от студентов с низкими показателями подвижности и силы нервных процессов. Высокий уровень когнитивной подвижности является одним из факторов, обусловливающим успешность обучения в вузе [12].

2. Показатели внимания: высокая и средняя устойчивость внимания при низких значениях концентрации внимания. Определение концентрации внимания показало, что 53 \% студентов имеют низкие значения, высокую концентрацию внимания продемонстрировали лишь $7 \%$ и, соответственно, средние значения были обнаружены у 40 \% студентов [14]. Низкий уровень концентрации внимания свидетельствует о флуктуации внимания, наличии непроизвольных скачков внимания, которые мешают целостному сосредоточенному восприятию информации, что, в свою очередь, может отрицательно влиять на запоминание лекционного материала, выполнения практических работ. Ввиду низкой концентрации внимания студенты могут допускать непроизвольные ошибки в вычислительных заданиях, «терять» логику изложения материала.

3. Баланс нервных процессов - для большинства респондируемых студентов сдвинут в сторону преобладания возбуждения. Полученные результаты 
позволяют предположить, что исследуемые нами студенческие группы имеет когнитивно возбудимый стиль: эмоционально неустойчивы, нетерпеливы, целеустремленны, склонны к переоценке своих способностей, помехонеустойчивы [16].

4. Кратковременная сенсорная память. Результаты нашего исследования показывают более высокий уровень кратковременного запоминания объема зрительной информации в сравнении с запоминанием объема вербально-слуховой информации [13]. Можно предположить, что такая особенность определяется психофизиологическими факторами, но в определенной степени может быть обусловлена повсеместным использованием обучающейся молодежью гаджетов, которые активируют прежде всего зрительную сенсорную систему.

5. Биоритмы - преобладание в студенческой популяции людей с дневным (54\%) и вечерним типом (33\%). Наличие тенденции «растягивать» индивидуальную минуту. Полученные результаты свидетельствуют о том, что большинство студентов, обучающихся в утреннюю смену (обследование проходило до эпидемии коронавируса, когда все студенты посещали занятия), находятся в состоянии хронического стресса вследствие несоответствия внутренних, эндогенных ритмов внешним, социально-навязанным. При нарушении биоритмологических закономерностей у студентов могут снижаться адаптационно-приспособительные возможности организма, что проявляется в ухудшении работоспособности, повышении утомляемости, нарушении сна, развитии неврозов [8].

6. Индивидуальный профиль моторной асимметрии - преимущественно правый. 67 \% обследуемых студентов были отнесены к типу с сильным правосторонним профилем по моторной и сенсорной асимметрии; 29 \% студентов были отнесены к типу с частичным правосторонним профилем; 3\% составили студенты с левосторонним профилем и 1 \% с неопределенным профилем [17]. Одними из качеств, присущих преимущественно правостороннему профилю являются формирование однозначного контекста, всеми понимаемого одинаково и необходимого для успешного общения между людьми; конвергентное мышление, проявляющееся в заданиях, у которых существует только одно правильное решение; поток мыслей «идет» по одному руслу (например, установление последовательности в схеме); преобладание вербального мышления, «речевой интеллект»; легкость воспроизведения фактов и затруднения, если нужно что-то придумать или привести пример, социальная адаптабельность [9].

7. Вегетативный баланс. Большинство студентов в нашем исследовании оказались с балансом отделов ВНС - нормотониками - 57 \%, 35 \% симпатико- тониками и 8\% ваготониками. Достаточно высокий процент симпатикотоников в обследуемой группе студентов свидетельствует о сниженных адаптационных ресурсах обучающейся молодежи. По данным О.А. Вангревич и соавторов взрослые симпатотоники с трудом поддаются обучению навыкам произвольной саморегуляции физиологических состояний, а также показывают сниженную реактивность к стимулам, повышенную тревожность и уязвимость к стрессовым воздействиям [3].

8. Другие признаки. Качества экстраверсии-интроверсии, нейротизма, силы процессов возбуждения и торможения в обследуемой группе продемонстрировали количественное и качественное разнообразие с отсутствием направленных тенденций. Следовательно, учет этих свойств в образовательном процессе должен осуществляться на уровне отдельных личностей, а не в групповом аспекте.

\section{Зак^ючение}

С учетом выявленных групповых характеристик психофизиологического статуса исследуемой группы студентов можно порекомендовать преподавателям и студентам следующие методические приемы (краткий итог):

- студентам с высокой подвижностью нервных процессов не перегружать нервную систему восприятием и переработкой сразу большого объема зрительной информации. Также им необходимо учиться распределять сенсорную нагрузку, развивать слуховые перцептивные процессы, давать отдых зрительной системе с целью профилактики астенопии - зрительного утомления;

- студентам с преобладанием процессов возбуждения учиться выдержанности, произвольной регуляции своих эмоциональных проявлений, способам сублимации нервно-психического напряжения в позитивное русло. Это могут быть занятия физической культурой и спортом, творческая и общественная деятельность;

- студентам с низкой концентрацией внимания не торопиться сдавать контрольные и самостоятельные работы, не перепроверив результаты. Если работа очень важная, лучше отложить её на какое-то время, а затем вернуться к проверке;

- студентам и преподавателям - составляйте план мероприятий, ведите дневник учета и контроля выполнения заданий в особенно напряженные для вас дни, недели. Потратив немного времени на составление этого графика работы, вы впоследствии сможете избежать большого количества неприятностей, связанных с вашей деятельностью

- студентам и преподавателям - чаще использовать логическую последовательность изложения материала. В обучении следует продумывать первоначальную подачу теоретического материала в 
различного рода логических схемах (когнитивная визуализация): «правополушарные» учащиеся получат возможность «увидеть» учебную задачу зрительно (в целостном образе), а «левополушарные» смогут разобраться в учебной проблеме по мере «продвижения» изложения материала согласно логике схемы. Акцентирование внимания на существенных сторонах изучаемой темы;

- преподавателям - формулировка выводов по поставленным образовательным проблемам и вопросам с определенной долей самостоятельности студентов;

- преподавателям - индивидуальные собеседования и задания, корректировка балльной оценки знаний с учетом психодинамических особенно- стей личности;

- преподавателям - учет биоритмов и работоспособности в учебном процессе;

- преподавателям - использование наглядности на лекциях и практических занятиях;

- преподавателям - увеличение количества заданий, предполагающих устный ответ студента(ов);

- студентам и преподавателям - учиться эмоциональной саморегуляции, так как именно из-за чрезмерного нервно-психического напряжения и неадекватных оценок самых разнообразных ситуаций у людей возникают вегетативные расстройства, проявляющиеся на физическом и психическом уровнях, в виде выраженных стресс-реакций.

\section{ЛИТЕРАТУРА}

1. Байгужина, О.В. Особенности адаптивных реакций вегетативной нервной системы и нейродинамических процессов организма студенток $19-20$ лет в зависимости от типа ментальной нагрузки: автореф. дисс... канд. биол. наук: 03.00.13; 19.00.02 / 0.В. Байгужина. - Челябинск, 2008. -148 с.

2. Брагина, Н.Н. Функциональные асимметрии человека [Текст] / Н.Н Брагина, Т.А. Доброхотова. - М.: Медицина, 1988. - 468 с.

3. Вангревич, 0.А. Игровое биоуправление и стресс-зависимые состояния / 0.А. Вангревич, О.Г. Донская, А.А. Зубков и др. // Бюллетень СО РАМН. 2004. T. $113,-$ N 3. - C. 53-60.

4. Временное положение по психофизиологическому обеспечению надежности профессиональной деятельности и сохранению здоровья персонала энергетических предприятий. РД 153-34.0-03.503-00: утв. Минздравом РФ, РАО «ЕЭС России» 18.06 .2000 г.

5. Литвинова, Н.А. Роль индивидуальных психофизиологических особенностей студентов в адаптации к умственной и физической деятельности [Текст]: автореферат дисс... д-ра биол. наук: 03.00.13 / Н.А. Литвинова. - Томск, 2008. - 38 с.

6. Мальцев, В.П. Психофизиологический статус студенток как фактор обеспечения учебно-профессиональной деятельности / В.П. Мальцев, Д.З. Шибкова, П.А. Байгужин // Вестник Сургутского государственного педагогического университета. - 2011. - № 2. - С. 163-170.

7. Мантрова, И.Н. Методическое руководство по психофизиологической и психологической диагностике / И.Н. Мантрова. - г. Иваново: 000 «Нейрософт», 2010. $-216 c$.

8. Моисеева, Н.И. Время в нас и время вне нас. / Н.И. Моисеева - Л.: Лениздат, 1991. - 156 с.

9. Пинчуков, А.Г. Успеваемость и типологические особенности проявления свойств нервной системы / А.Г. Пинчуков // Оптимальное соотношение между умственной и физической деятельностью у студентов педагогических институтов. - Л., 1976. - С. 113-119.

10. Русалов, В.М. Некоторые основания специальной теории индивидуальности человека / В.М. Русалов // Интегральное исследование индивидуальности: теоретические и педагогические аспекты. - Пермь, 1988. - С. 3-10.

11. Холодная, М.А. Когнитивные стили и интеллектуальные способности М.А. Холодная //Психол. журн., 1992. - Т.13. - № 3. - С. 84-93.

12. Юрченко, И.А. Психофизиологические корреляты успешности обучения студентов в вуза: диссертация. .. кандидата медицинских наук: 19.00 .02 / Юрченко Ирина Александровна; [ Место защиты : ГОУ ВПО «Военно-медицинская академия»]. - Санкт-Петербург, 2010.

13. Ядрищенская, Т.В. Исследование возрастных изменений кратковременной сенсорной памяти / Т.В. Ядрищенская // Психология, педагогика, образование: актуальные и приоритетные направления исследований: сборник статей Международной научно-практической конференции (11 апреля 2018 г, г. Оренбург). - Уфа.: ОМЕГА САЙНС, 2018. - С.247-250.

14. Ядрищенская, Т.В. Корреляционные отношения и гендерные особенности характеристик внимания / Т.В. Ядрищенская // Ученые записки Забайкальского государственного университета. - №1 (60) - 2015.

15. Ядрищенская, Т.В. Лабораторный практикум по физиологии физического воспитания и спорта: учебно-метод. пособие для студентов факультета физической культуры / Т.В. Ядрищенская, В.В. Мельников. - Хабаровск: Изд-во Дальневосточ. гос. гуманит. ун-та, 2007. - 74 с.

16. Ядрищенская, Т.В. Психофизиологические особенности студентов и когнитивные стили обучения / Т.В. Ядрищенская, Н.П. Долгих // Материалы международной научно-методической конференции «Проблемы высшего образования». - Том І. - ФГБОУ ВО Тихоокеанский государственный университет, Хабаровск г, 2016. - С. 243-246.

17. Ядрищенская, Т.В. Психофизиологические показатели в аспекте адаптации студентов к учебной деятельности в вузе / Т.В. Ядрищенская // Наука и образование на российском Дальнем Востоке: современное образование и перспективы развития. - Т2. - Тихоокеанский государственный университет, Хабаровск, 2016. - С. 380-385. 